\title{
RELASI ANTARA PENGINJILAN DAN PEMURIDAN UNTUK PERTUMBUHAN GEREJA
}

\section{Dorce Sondopen}

Kaprodi S1 Pendidikan Agama Kristen Sekolah Tinggi Teologi Excelsius

\begin{abstract}
The mission can relate evangelism and discipleship so as to have a close relationship and a unity that can not be decided. This is also useful and beneficial to the growth of the church. The growth of evangelical churches are seeking to make disciples are in the process of discipleship intact that can be sorted by viewing aspects of qualitative, quantitative organic and focus inseparable from one another.
\end{abstract}

Keywords: mission, relationship, evangelism, discipleship, church growth

\begin{abstract}
Abstraks
Misi dapat merelasikan penginjilan dan pemuridan sehingga mempunyai hubungan yang erat dan merupakan satu kesatuan yang tidak dapat diputuskan. Hal inilah yang juga berguna dan bermanfaat bagi pertumbuhan gereja. Pertumbuhan gereja adalah penginjilan yang mencari untuk memuridkan di mana terjadi proses pemuridan yang utuh yang dapat dipilah dengan melihat aspek kualitatif, kuantitatif, organik dan fokus yang tidak terpisahkan satu dari yang lainnya.
\end{abstract}

Kata Kunci: misi, relasi, penginjilan, pemuridan, pertumbuhan gereja 


\section{PENDAHULUAN}

Pertumbuhan gereja adalah hal yang sangat dibutuhkan gereja pada masa kini. Pasalnya, jumlah jemaat yang saat ini datang untuk beribadah terus menurun. Melihat ke kancah internasional, bangunan fisik gereja banyak yang tidak dipergunakan dengan sebagaimana mestinya. Gedung-gedung gereja tersebut dijual dan kemudian direstorasi ulang untuk menjadi fasilitas publik lainnya seperti hotel, restaurant, bioskop, masjid, bahkan bar. Walaupun begitu masih cukup banyak bangunanbangunan gereja yang dapat bertahan, namun hanya memiliki jemaat para kaum lansia dan itupun berjumlah sedikit.

Di Indonesia pun gereja juga mengalami pergoncangan. Sulitnya membangun sarana ibadah (bagunan fisik gereja) dan larangan dari masyarakat sekitar yang melarang jalannya ibadah membuat pertumbuhan gereja mengalami kendala. Namun, perlu diketahui bahwa pertumbuhan gereja tidak hanya berbicara tentang pertumbuhan dan perkembangan gereja secara fisik saja. Pertumbuhan gereja juga berbicara tentang pertumbuhan di dalam jemaat itu sendiri.

Dalam pertumbuhan gereja tidak hanya peran pastoral saja yang dibutuhkan. Peranan misi pun juga dibutuhkan untuk merelasikan penginjilan dan pemuridan sehingga memiliki hubungan yang erat.
Pertumbuhan gereja adalah penginjilan yang mencari untuk memuridkan di mana terjadi proses pemuridan yang utuh yang dapat dipilah dengan melihat aspek kualitatif, kuantitatif, organik, dan fokus yang tidak terpisahkan satu dari yang lainnya.

\section{ANALISIS DAN HASIL PENELITIAN}

\section{Pengertian Mission}

Istilah mission atau misi (dipakai dalam Bahasa Inggris, Jerman dan Belanda dengan istilah "missie" dipergunakan dalam kalangan Gereja tetapi umumnya menggunakan kata "zending") berasal dari kata Latin "missio" yang diangkat dari kata "mittere" (berkaitan dengan kata "missum"), yang berarti "to send" (mengirim atau mengutus), "act of sending; being sent or delegated by authority/ person sent, etc". Padanan dari kata ini dalam bahasa Yunani adalah "apostello". Kata "apostello" ini tidak berarti mengirim atau kirim (ретро) secara umum, melainkan lebih dari pada itu adalah "mengirim dengan otoritas". Di sini, otoritas hidup di dalam “oknum” yang mengirim dan yang dikirim. Otoritas menjadi kekuatan kegiatan yang mengisi pengiriman dan yang dikirim.

Arie de Kuiper merumuskan pengertian mission ada tiga hal sebagai berikut: Pertama, "mission ecclesiae" (pengutusan gereja atau pekerjaan misioner dari jemaat Kristen sepanjang sejarah dunia). 
Kedua, "Missio Christi" adalah pengutusan

Kristus dalam arti: (1) Kristus mengutus murid-murid-Nya; (2) Kristus diutus Allah (Yoh. 20:21); (3)"Mission Dei" adalah keseluruhan pekerjaan Allah untuk menyelamatkan dunia: pemilihan Israel, pengutusan para nabi kepada Israel dan kepada bangsa-bangsa sekitarnya, pengutusan Kristus kepada dunia, pengutusan rasul-rasul dan pekabaranpekabaran Injil kepada bangsa-bangsa. Di sini Allah adalah Pengutus Agung. ${ }^{153}$ Allah adalah sumber, inisiator, dinamisator, pelaksana, dan penggenap misi-Nya. Jadi, Allah sendirilah yang aktif dan keaktifan umat Allah adalah respon tanggung jawab yang berada dalam lingkup keaktifan Allah.

Disisi lain, David W. Ellis mengatakan bahwa:

Misi adalah panggilan yang tritunggal untuk menyatakan Kristus kepada dunia dengan jalan proklamasi, kesaksian dan pelayanan, supaya dengan kuasa Roh Kudus Allah dan Firman-Nya, manusia dibebaskan dari egoisme dan dosanya dan dengan tindakan Allah dilahirkan kembali sebagai anak-anak Allah dan menjadi anggota keluarga Allah dengan jalan percaya akan Dia melalui Yesus Kristus, yang diterimanya sebagai Juruselamatnya pribadi dan dilayaninya sebagai Tuhannya dalam persekutuan tubuhNya, yaitu Gereja, untuk kemudian menyatakan Dia kepada dunia. ${ }^{154}$

Penafsiran tradisional mengenai hakekat misi telah mulai diperbaharui pada

${ }^{153}$ Arie de Kuiper, Missiologia (Jakarta: BPK Gunung Mulia, 2003) 10.

${ }^{154}$ David W. Ellis, Gumulan Misi Masa Kini (Jakarta: BPK Gunung Mulia, 1975), 22-23. abad ke-20. Berkaitan dengan hal tersebut, maka Yakob Tomatala mendefisikan misi adalah rencana pengutusan Allah (Missio Dei) yang kekal yang (untuk) membawa shalom kepada manusia (umat-Nya) dan segenap ciptaan-Nya demi kejayaan kerajaan-Nya. ${ }^{155}$ Misi (mission) adalah tugas-tugas (missions) yang dimandatkan oleh Allah kepada umat-Nya untuk menjadi "alat shalom-Nya kepada manusia dari segala bangsa". ${ }^{156}$

\section{$\underline{\text { Relasi Penginjilan dan Pemuridan }}$}

Pengertian Penginjilian

Misi tidak lepas dari pengertian penginjilan di mana keduanya saling berhubungan erat. Misiologi telah dianggap sebgai induk dari semua ilmu misi termasuk ilmu penginjilan. Jadi, dalam misi ada penginjilan dan dalam penginjilan dapat ditemukan misi (pengutusan). Penginjilan berasal dari kata "Injil" (bahasa Arab), yang dalam bahasa Yunani Perjanjian Baru menggunakan kata-kata sebagai berikut: Pertama, kata "euangelion". Kata "euangelion", pertama kali digunakan dalam bidang militer, kemudian berkembang arti "euangelion" menjadi adalah upah yang diberikan kepada seorang pembawa berita kemenangan dari medan pertempuran.

\footnotetext{
${ }^{155}$ Yakob Tomatala, Teologi Misi (Jakarta:YT Leadership Foundation, 2003), 24. ${ }^{156}$ Ibid., 26.
} 
Dalam perkembangannya kemudian, kata "euangelion" beralih kepada "berita kemenangan" itu sendiri. Ketika kekristenan hadir, kata "euangelion" dipinjam dan digunakan dalam istilah kekristenan dengan arti "berita sukacita atau kabar baik dari Allah tentang Yesus Kristus dan karya penebusan-Nya bagi dunia" (Rm. 1:16; 1 Kor. $15: 1-4) .{ }^{157}$

Kedua, kata "prosthetics" (asal kata "prostithenal"; Kis. 2:41, 47; 11:24) menunjuk pada pengertian misi. Kata "prosthetics" adalah TUHAN menambahkan bilangan orang-orang yang diselamatkan ke dalam jemaat-Nya". ${ }^{58}$ Kata "prosthetics" juga dikaitkan dengan kata "auxanics", yang artinya " bertambah dan berkembang keluar" dan kata "halieutics", yang artinya "menjala orang". Ketiga, kata "apostolate" (apostolate). ${ }^{159}$ Kata "apostolate" menekankan tentang "apostolic martyria" (saksi) dengan tugas "didakhe" (mengajar), dan kata "kerygma" (pemberitaan) tentang Yesus Kristus.

Secara filosofis, penginjilan adalah "rancangan dan karya Allah yang menghimpun bagi diri-Nya suatu umat untuk bersekutu, menyembah dan melayani Dia secara serasi-utuh bagi kejayaan kerajaan-

${ }^{157}$ Yakob Tomatala, Teologi Misi, 17.

${ }^{158}$ Istilah ini dikembangkan oleh Abraham Kuyper dalam buku yang ditulis J.H. Bavinck, An Introduction to the Science of Mission (1960), xvii.
Nya”. Secara operasional, penginjilan adalah "memberitakan tentang Yesus Kristus dalam kuasa Roh Kudus kepada orang berdosa (dalam berita) yang disampaikan dengan penuh keyakinan agar orang berdosa tersebut bertobat dan menerima Yesus Kristus sebagai Juruselamat, menjadi anggota gereja yang bertanggung jawab untuk memuridkan orang lain guna memenangkan dunia bagi kejayaan Kristus, sehingga membawa kemuliaan bagi Allah. Dengan kata lain, penginjilan adalah suatu proklamasi Injil Yesus Kristus yang berkuasa, mengena, dapat dimengerti, agar manusia bertobat kepada Tuhan Yesus.

Pengertian Pemuridan

Istilah "pemuridan" (discipleship) seringkali dikaitkan dengan Kisah Para Rasul 6:7, yang berikata: "Firman Allah makin tersebar, dan jumlah murid di Yerusalem makin bertambah banyak". Frasa ini menunjuk pada terjadinya proses orangorang yang memenangkan kepada Kristus dan kemudian membimbingnya dari saat pertobatannya sampai menjadi seorang murid yang kokoh, berserah, mengabdi, berbuah, dan dewasa; dan pada suatu waktu dapat mengulangi proses itu dalam kehidupan orang lain. ${ }^{160}$ Berkaitan hal tersebut, maka

\footnotetext{
${ }^{159}$ Tokoh-tokoh yang menggunakan istilah "apostolate" untuk menjelaskan mengenai misi adalah A. van Ruler, J.C. Hoiekedijk dan A. Kuper.

${ }^{160}$ LeRoy Eims, Pemuridan Seni yang Hilang (Bandung: LLB, 2002), 11.
} 
Marvin Leech mengatakan bahwa roda kehidupan murid Yesus bertujuan Christlike (Yoh. 15:5; Gal. 2:20). Tujuan pemuridan adalah pelipatgandaan. ${ }^{161}$ Karena itu Robert E. Coleman mengatakan bahwa proses pemuridan mencakup delapan hal sebagai berikut: ${ }^{162}$

Pertama, "pemilihan murid"163 di mana Lukas 6:13 berkata: "Ketika hari siang, Ia (Yesus) memanggil murid-murid-Nya, lalu memilih dari antara dua belas orang, yang disebut-Nya rasul". Siapakah yang harus menjadi murid? (1) Ia adalah seseorang yang mau belajar, bukan orang yang sangat menonjol; (2) Konsentrasi pikirannya tidak bercabang-cabang (memberikan sepenuh dirinya dan waktunya untuk Yesus); (3) Memusatkan perhatian kepada pribadi-pribadi: dunia dapat berubah hanya jika orang-orang di dalamnya telah diubah lebih dahulu.

Orang-orang yang dipilih oleh Yesus adalah orang-orang biasa - penjala ikan, pemungut cukai, dan lain sebagainya. Pada saat sebelum Ia memilih orang-orang yang akan Ia latih, Ia berdoa sepanjang malam (Luk. 6:12,13). ${ }^{164}$ Bagi LeRoy Eims bahwa

${ }^{161}$ Marvin Leech, Pemuridan III (Semarang: STTBI, 1995), 1-3.

${ }^{162}$ Baca Robert E. Coleman, Rencana Agung Penginjilan (Bandung: Kalam Hidup) 1993; baca juga Marvin Leech, Pemuridan V (Semarang: STTBI, 1995), vii-5.

${ }^{163}$ Baca bagian "Selection of Disciples" Robert E. Coleman, The Master Plan of Evangelism (Old Tappan: Fleming H. Revell Company, 1964), apa yang dilakukan Yesus adalah strategi penting dalam pemilihan. Yesus tidak terburu-buru menangkap orang pertama yang menunjukan minat. ${ }^{165}$ Tujuan Yesus memilih dua belas murid adalah "untuk menyertai Dia dan untuk diutus-Nya memberitakan Injil"' (Mrk. 3:14). Dengan demikian Yesus melakukan hubungan akrab dengan para murid dan membinanya. Hal tersebut menjadi jelas di mana Yesus berkata: "Bukan kamu yang memilih Aku, tetapi Akulah yang memilih kamu. Dan Aku telah menetapkan kamu supaya kamu pergi dan menghasilkan buah dan buahmu itu tetap, supaya apa yang kamu minta kepada Bapa dalam nama-Ku, diberikan-Nya kepadamu" (Yoh. 15:16).

Kedua, "persekutuan" di mana kata persekutuan (koinonia). Kata "koinonia" mengacu pada ikatan kasih yang mempersatukan seluruh umat Allah. Dalam bahasa Inggris adalah "fellowship" adalah "two fellows in one ship" (dua orang dalam satu kapal). Hal itu menunjukkan adanya kemitraan. Jadi, persekutuan adalah suatu yang lebih dari sekadar berjabat tangan, menepuk bahu, senyuman ramah dan

Marvin Leech, Pemuridan II (Bandung: LLB, 1988) 57-61.

${ }^{164}$ Peter Wagner, Gereja yang Berdoa (Yogyakarta: Yayasan Andi, 1993) mengatakan bahwa doa harus menjadi prioritas yang utama dalam gereja. Doa harus mendapat bintang lima dalam urutan program gereja.

${ }^{165}$ LeRoy, Pemuridan Seni yang Hilang, 24. 
sambutan hangat seseorang. Semua hal tersebut memang termasuk di dalamnya.

Persekutuan bukan hanya sekadar ramah-tamah sambil menikmati kopi panas dan makan kecil seusai kebaktian. Persekutuan lebih dari hal-hal tersebut di atas. Persekutuan adalah suatu wujud kasih yang murni, yang berhasil menangani dan mengatasi berbagai permasalahan yang cenderung memecah-belah umat Allah. Persekutuan merupakan suatu ketetapan hati para anggota gereja untuk saling mengasihi dan bersatu. Persekutuan tidak akan membiarkan suatu kesalahan menimbulkan perpecahan. Persekutuan adalah kunci untuk masuk ke dalam kehidupan yang sebenarbenarnya di dalam gereja. ${ }^{166}$

Ketiga, "penyediaan" di mana Matius 11:29 berkata "Pikullah kuk yang Kupasang”. Frasa ini adalah Yesus menghendaki ketaatan murid-murid-Nya dalam proses pembentukan di mana ia harus siap melalui "jalan Salib". Lukas 16:13 berbunyi: "Seorang hamba tidak dapat mengabdi kepada dua tuan. Karena jika demikian ia akan membenci yang seorang dan mengasihi yang lain, atau ia akan setia kepada yang seorang dan tidak mengindahkan yang lain. Kamu tidak dapat mengabdi kepada Allah dan kepada

${ }^{166}$ Darrell W. Robinson, Total Church Life (Bandung: LLB, 2004), 72-72.
Mamon". Di sini dibutuhkan "penyerah diri" secara total, sebab taat adalah belajar.

Keempat, "pengurapan" di mana Yohanes 20:22 dikatakan "terimalah Roh Kudus". Frasa ini mengarahkan bahwa Yesus menghendaki ketaatan pada pengikutNya karena hanya dengan demikianlah mereka dipenuhi oleh Roh-Nya. Dengan Roh-Nya para murid dapat melihat kasih Allah bagi dunia yang terhilang ini. Yesus ingin menanamkan pengertian bahwa hidupNya mencerminkan maksud Allah yang kekal untuk menyelamatkan umat-Nya. Hal tersebut bukan hanya teori, melainkan secara aplikasi. Jadi, diperlukan "pengudusan" diri terus menerus melalui pelayanan kasih kepada orang lain.

Kelima, "percontohan" di mana Yohanes 13: 15 berkata: "Aku telah memberikan suatu teladan kepada kamu". Yesus memperlihatkan cara hidup-Nya: berdoa, menggunakan Alkitab, memenangkan jiwa, mengajar dengan wajar, dan segalanya. Hal itu dilakukan dengan harapan dapat menjadi teladan bagi para murid dan orang lain.

Keenam, "pengutusan" di mana Matius 4:19 berkatak: "Kamu akan kujadikan penjala manusia”. Frasa ini menegaskan bahwa Yesus memberi tugas kepada para murid agar menjala manusia 
(penginjilanl). Tetapi pengutusan ini merupakan proses latihan (praktek) muridmurid agar pada suatu ketika mereka dapat mengambil alih pekerjaan-Nya untuk memberitakan Injil keselamatan kepada dunia. Metode yang digunakan diharapkan mencontoh metode yang telah Yesus lakukan sepanjang para murid mengikuti Yesus.

Ketujuh, "pengawasan" di mana Markus 8:17 berkata: "belum jugakah kamu paham?" Dalam proses pengutusan; latihan; praktek (pengutusan pertama; Mat. 10:5; Mrk. 6:7; Luk. 9:102) maka Yesus mengawasi para murid-Nya. Yesus mengevaluasi para murid yang telah praktek, lalu mereka kembali pelayanan bersamasama. Pada waktu tertentu Yesus kembali mengutus mereka (Mrk. 6:7; Luk. 10: 2-16; Luk. 9:52).

Kedelapan, “pelipatgandaan" di mana Yohanes 15:16 berkata: "pergi dan menghasilkan buah". Para murid adalah pelopor memenangkan jiwa sebanyak mungkin. Hal tersebut dituangkan dalam Amanat Agung Yesus (Mat. 28:19; Mrk. 16:15). Berkaitan dengan pelipatgandaan murid, maka LeRoy Eims mengatakan:

Langkah pertama untuk membentuk sekelompok orang yang berminat bagi pemuridan ialah motivasi. Mereka harus

${ }^{167}$ Sasarannya adalah melihat munculnya sekelompok orang yang mempelajari Firman Tuhan secara pribadi dengan teratur dan yang berdoa secara efektif. Orang-orang itu hidup di dalam persatuan dengan Yesus Kristus yang vital hari demi hari, dan melalui hidup mereka kehidupan Yesus Kristus diberi motivasi pada dua arah - ke dalam dan ke luar. Secara ke dalam mereka harus diberi motivasi untuk mengadakan persekutuan dengan Yesus Kristus ${ }^{167}$. Dan secara ke luar mereka harus menjadi saksi bagi Kristus Yesus. Proses keseluruhannya harus dijalankan dengan banyak doa dan pikiran. Mungkin proses itu dapat digambarkan dengan sebuah proyek bangunan baru. ${ }^{168}$

Dari pemahaman antara penginjilan dan pemuridan di atas, maka dapat direlasikan bahwa keduanya mempunyai hubungan yang erat dan merupakan satu kesatuan yang tidak dapat diputuskan. Penginjilan merupakan langkah awal dari pemuridan. Penginjilan sebagai salah satu dimensi esensial, yang pemberitaan keselamatan di dalam Kristus kepada mereka yang tidak percaya kepada-Nya, memanggil mereka untuk bertobat dan meninggalkan hidup yang lama, memberitakan pengampunan dosa dan mengundang mereka untuk menjadi anggota-anggota yang hidup dari komunitas Kristus di bumi dan untuk memulai kehidupan pelayanan kepada orang lain di dalam kuasa Roh Kudus. ${ }^{169}$ Sedangkan pemuridan adalah kegiatan yang lebih mengarah memotivasi dan melatih orang-orang percaya dewasa rohani agar mereka dengan sepenuh hati menyerahkan diri kepada Allah untuk menjadi murid. Dengan demikian, dengan kasih dan

mengalir dalam kuat kuasa penyelamatan kepada orang lain di sekitar mereka.

Hilang, 52

${ }^{168}$ LeRoy Eims, Pemuridan Seni yang

${ }^{169}$ David J. Bosch, Transformasi Misi Kristen (Jakarta: BPK Gunung Mulia, 1999), 16. 
sukacita, ia selalu haus memberitakan Injil dan kembali melakukan pemuridan seperti pada masa ia diproses menjadi seorang murid.

\section{Gereja Lokal sebagai Pusat Proses Misi}

Agar dapat memotivasi jemaat melakukan penginjilan apalagi pemuridan, maka gereja lokal adalah sarana efektif mewujudkan tujuan tersebut. ${ }^{170}$ Direlasikan dengan hal tersebut, dikatakan bahwa gereja yang bertumbuh perlu menekankan pelayanan yang seimbang ${ }^{171}$ sebagai berikut: Pertama, ibadah yang penuh kuasa: suasana doa, puji-pujian, jemaat bersaksi, khotbah yang diurapi, dan undangan menerima Yesus sebagai Juruselamat; Kedua, pelayanan kerohanian yang kuat: kelompok-kelompok PA; Ketiga, dorongan untuk menginjili dengan dinamis: komitment memenangkan jiwa. Keempat, pelayanan pastoral yang konsisten: setiap anggota harus membimbing secara kerohanian. Kelima, persekutuan yang mempersatukan dan yang bertumbuh. ${ }^{172}$

Pemikiran di atas didukung oleh Dean Wiebracht dengan merumuskan beberapa tahap yang perlu dilakukan seseorang menjadi dewasa rohani sebagai

${ }^{170}$ J. Riberu, "Masalah Pendidikan pada Umumnya dan Pendidikan Agama pada khususnya", Identitas \& Ciri Khas Pendidikan Kristen di Indonesia (2000), 170.

${ }^{171}$ Gereja yang seimbang adalah: gereja yang berpusat kepada Kristus (Kol. 3:23), gereja yang berpusat kepada orang, gereja yang berpusat pada berikut: Pertama, menangkap visi Allah di mana gereja wajib melakukan memberitaan Injil. Kedua, setelah mempunyai visi, maka ia mulai menentukan prioritas di mana doa menjadi kekuatan misi dan pendeta menjadi motivator jemaat agar termotivasi melakukan kegiatan misi. Ketiga, memetakan jalan di mana tujuan yang mau arah harus jelas dengan mengembangkan metode apa agar tujuan itu tercapai. Keempat, setelah mempunyai metode untuk mencapai tujuan, maka tim perlu dibangun: mempersiapkan misionaris. Kelima, memperluas pengaruhnya dengan cara: (a) mengutus para pekerja, (b) menyediakan pendanaan misi, (c) tetap dalam jalur meski badai mengoyangkan, dan (d) berbagi apa yang sudah mereka pelajari dengan tim. ${ }^{173}$

$$
\text { Jadi, Darrell W. Robinson, }
$$
mengatakan bahwa kalau gereja lokal hidup bersama Kristus dan mengalami kehadiranNya, maka timbullah belas kasihan, kepedulian, dan kerinduan untuk melayani dalam diri jemaat-Nya. Dari kepedulian semacam ini lahirlah pelayanan dalam bidang pendidikan, sosial, kesehatan, dan lain-lain. Semuanya ini adalah pelayanan yang memenuhi kebutuhan masyarakat dan

Alkitab (2 Tim. 2:16-17), gereja yang berpusat pada ketaatan (Yak. 1:22).

${ }^{172}$ Darrell W. Robinson, Total Church Life, 96-97.

${ }^{173}$ Baca Dean Wiebracht, Menjawab Tantangan Amanat Agung (Yogyakarta: Kanisius, 1997). 
lingkungannya. ${ }^{174}$ Dengan demikian, Dean Wiebracht menggunakan istilah "Gereja Amanat Agung”. Gereja Amanat Agung adalah sebuah gereja yang aktif berdoa, berencana dan bekerja menuju penggenapan Amanat Agung. Gereja harus aktif, berpikir, membuat rencana dan berdoa untuk penginjilan dunia. Para pemimpin gereja telah menjadikan penginjilan dunia suatu prioritas yang kasat mata dalam kehidupan dan tujuan gereja. Ada penggerakan misi yang setia akan janji. Mungkin mereka menamakan diri suatu komisi misi. Mereka memandang diri mereka sendiri sebagai para pelaku perubahan dan membantu gereja mereka melakukan bagian tugasnya dalam menggenapi Amanat Agung. ${ }^{175}$

Agar gereja "Amanat Agung" dapat berjalan, maka David Mays memberi saran sebagai berikut:

Iklankan dengan berani, tunjukkan kepada kami strateginya, tarik mereka kepada makna (hidup berarti bagi Allah), berikan pengalaman [bertumbuh karena pengalaman], buatlah supaya bersifat pribadi (beritanya), tawarkan pilihan, izinkan komitmen jangak pendek, hargai waktu yang tersedia, bekerjalah melalui berbagai relasi, minta masukan dari para pemimpin, buatlah gagasan-gagasan kita sebagai modal, lihatkan kita dalam kegiatan setempat (lokal). ${ }^{176}$

\section{Pertumbuhan Gereja}

Misi juga tidak dapat dipisahkan dengan kata "Church Growth" (pertumbuhan gereja). Pertumbuhan gereja adalah penginjilan yang mencari untuk memuridkan "ta ethne" (segala bangsa) di mana terjadi proses pemuridan yang utuh yang dapat dipilah dengan melihat aspek kualitatif, kuantitatif, organik dan fokus yang tidak terpisahkan satu dari yang lainnya.

Pertumbuhan gereja adalah kehendak Allah yang menghendaki gereja-Nya bertumbuh (Kis. 2: 40-47). Istilah pertumbuhan gereja dapat juga disebut "pemuridan" (discipleship). Dalam Kisah Para Rasul 6:7 dikatakan "Firman Allah makin tersebar, dan jumlah murid di Yerusalem makin bertambah banyak”. Frasa ini menunjuk pada terjadinya proses orangorang yang memenangkan kepada Kristus dan kemudian membimbingnya dari saat pertobatannya sampai menjadi seorang murid yang kokoh, berserah, mengabdi, berbuah, dan dewasa; dan pada suatu waktu dapat mengulangi proses itu dalam kehidupan orang lain. ${ }^{177}$

Buah penginjilan di atas menjadi nyata dalam PB di mana tercatat asal usul pertumbuhan gereja-gereja abad pertama

${ }^{176}$ David Mays, Bagaimana Membuat Jemaat Anda Terlibat dalam Misi Penginjilan (Bandung: ACMC, 1997), 31-32.

${ }^{177}$ LeRoy Eims, Pemuridan Seni yang Hilang (Bandung: LLB, 2002), 11. 
sebagai berikut: Gereja pertama di Yerusalem dimulai di ruang atas dengan jumlah murid sebanyak 120 orang (Kis. 1:15). Pada hari Pentakosta 3.000 orang dibaptiskan, diberi pelajaran Firman Allah, dan ditambahkan kepada sidang di Yerusalem (Kis. 2: 41-42). Secara terperinci Dokter Lukas yang menulis Kitab Kisah Para Rasul mencatat adanya pola pertumbuhan sejak hari Pentakosta sampai kepada pemeriksaan dan pengurungan para murid yang mula-mula. Keanggotaan sidang di Yerusalem menjadi berjumlah 5.000 (Kis. 4:4). Di sini ditekankan pada "bertambahnya" jumlah orang yang percaya kepada Tuhan, baik laki-laki maupun perempuan (Kis 5:14). Waktu itu jumlah murid semakin "bertambah banyak" (Kis 6: 1,7), maka sejak itu baik dalam Kisah Para Rasul maupun Surat-surat Para Rasul dalam PB menekankan bahwa pentingnya "pelipatgandaan jemaat" maupun anggota jemaat. Dalam waktu kurang dari 40 tahun jemaat-jemaat terbentuk di kota-kota besar yang dikenal pada waktu itu. ${ }^{178}$

\section{KESIMPULAN}

Dalam misi ada penginjilan dan dalam penginjilan dapat ditemukan misi (pengutusan). Penginjilan adalah suatu proklamasi Injil Yesus Kristus yang Hilang, 11. berkuasa, mengena, dapat dimengerti, agar manusia bertobat kepada Tuhan Yesus. Tujuan pemuridan adalah pelipatgandaan. proses pemuridan mencakup delapan hal sebagai berikut: pemilihan murid, persekutuan, penyediaan, pengurapan, percontohan, pengutusan, pengawasan, dan pelipatgandaan. Dari pemahaman antara penginjilan dan pemuridan maka dapat direlasikan bahwa keduanya mempunyai hubungan yang erat dan merupakan satu kesatuan yang tidak dapat diputuskan. Penginjilan merupakan langkah awal dari pemuridan. Dan pemuridan adalah kegiatan yang lebih mengarah memotivasi dan melatih orang-orang percaya dewasa rohani agar mereka dengan sepenuh hati menyerahkan diri kepada Allah untuk menjadi murid. Misi juga tidak dapat dipisahkan dengan kata "Church Growth" (pertumbuhan gereja). Pertumbuhan gereja adalah penginjilan yang mencari untuk memuridkan.

\section{DAFTAR PUSTAKA}

$\underline{\text { Buku }}$

Bavinck, J.H. An Introduction to the Science of Mission. 1960.

Bosch, David J. Transformasi Misi Kristen. Jakarta: BPK Gunung Mulia, 1999.

Coleman, Robert E. Rencana Agung Penginjilan. Bandung: Kalam Hidup, 1993.
${ }^{178}$ LeRoy Eims, Pemuridan Seni yang 104 | Vol. 4 No. 1 (Juli-Desember 2019) 
Coleman, Robert E. The Master Plan of Evangelism. Old Tappan: Fleming $\mathrm{H}$. Revell Company, 1964.

Eims, LeRoy. Pemuridan Seni yang Hilang. Bandung: LLB, 2002.

Ellis, David W. Gumulan Misi Masa Kini. Jakarta: BPK Gunung Mulia, 1975.

Gerber, Vergil. Pedoman Pertumbuhan Gereja/Penginjilan. Bandung: Kalam Hidup, 1973.

Kirk, Andrew J. Apa itu Misi. Jakarta: BPK Gunung Mulia, 2012.

Leech, Marvin. Pemuridan I. Bandung: LLB, 1987.

Leech, Marvin. Pemuridan II. Bandung: LLB, 1988.

Leech, Marvin. Pemuridan III. Semarang: STTBI, 1995.

Leech, Marvin. Pemuridan V. Semarang: STTBI, 1995.

Mays, David.Bagaimana Membuat Jemaat Anda Terlibat dalam Misi Penginjilan. Bandung: ACMC, 1997.
Robinson, Darrell W. Total Church Life. Bandung: LLB, 2004.

Tomatala, Yakob. Teologi Misi. Jakarta: YT Leadership, 2004.

Vine, W.E. Expository Dictionary of New Testament Words. McLean: MacDonald Publishing Company, tp. th.

Wiebracht, Dean. Menjawab Tantangan Amanat Agung (Yogyakarta: Kanisius, 1997.

$\underline{\text { Jurnal }}$

Riberu, J. "Masalah Pendidikan pada Umumnya dan Pendidikan Agama pada khususnya", Identitas \& Ciri Khas Pendidikan Kristen di Indonesia (2000). 